\title{
Exploring the Relationship between LST, LULC and NDVI in Saïss Plain using Geospatial Techniques
}

\author{
Manal EL GAROUANI ${ }^{1}$, Mhamed AMYAY ${ }^{2}$, Abderrahim LAHRACH ${ }^{3}$ and Hassane JARAR OULIDI ${ }^{4}$ \\ ${ }^{1}$ Sidi Mohamed Ben Abdallah University, FST-Fez, B.P. 2202, Route d'Imouzzer, Fez, Morocco \\ ${ }^{2}$ Sidi Mohamed Ben Abdallah University, FLSH Saïss-Fez, B.P. 59 Route d'Imouzzer, Fez, Morocco \\ ${ }^{3}$ Sidi Mohamed Ben Abdallah University, ENSA - Fez, B.P. 72, Km 5 Route d'Imouzzer, Fez, Morocco \\ ${ }^{4}$ Hassania School for Public Works Engineering, B.P. 8108, Km 7 Route d'El Jadida, Casablanca, Morocco
}

\begin{abstract}
Land use/land cover (LULC) change has been confirmed that have a significant impact on climate through various pathways that modulate land surface temperature (LST) and precipitation. However, there are no studies illustrated this link in the Saïss plain using remote sensing data. Thus, the aim of this study is to monitor the LST relationship between LULC and vegetation index change in the Saïss plain using GIS and Remote Sensing Data. We used 18 Landsat images to study the annual and interannual variation of LST with LULC (1988, 1999, 2009 and 2019). To highlight the effect of biomass on LST distribution, the Normalized Difference Vegetation Index (NDVI) was calculated, which is a very good indicator of biomass. The mapping results showed an increase in the arboriculture and urbanized areas to detriment of arable lands and rangelands. Based on statistical analyzes, the LST varies during the phases of plant growth in all seasons and that it is diversified due to the positional influence of LULC type. The variation of land surface temperature with NDVI shows a negative correlation. This explains the increase in the surface temperature in rangelands and arable land while it decreases in irrigated crops and arboriculture.
\end{abstract}

Keywords: Land surface temperature, LULC, NDVI, Landsat image, GIS, Saïss Plain, Morocco

\section{I.INTRODUCTION}

At the issues on global change, dynamics characterization linked to the earth's surface transformations, for example: the extension of agricultural areas, desertification, urban sprawl, etc. are essential. In this sense, much effort has been devoted to the determination of the land surface temperature from remote sensing data. The extraction of LST has been the subject of several studies $[1,2,3,4,5,6,7,8]$ because it's used in several applications, such as evapotranspiration modelling [9], soil moisture estimation [10], climatic, hydrological, ecological and biogeochemical studies [11-12]. Therefore, it's very important to have access to reliable Ts estimation at large spatial and temporal scales.

Land surface temperature is one of the most important environmental parameters used to determine the energy and matter exchange between the earth's surface and the lower layer of the atmosphere [13]. LULC change has been confirmed to have a significant impact on climate through various pathways that modulate surface temperature and precipitation [14-15]. However, there are no studies illustrated this link in the
Saïss Plain using satellite observations. This contribution concerns the use of geospatial techniques to study the relationship between LST, LULC and NDVI in the Saïss plain during the period from 1988 to 2019.

\section{II.MATERIALS AND METHODS}

\subsection{Research area and data}

Saïss plain is located in northern Morocco with an area of about $2260 \mathrm{~km}^{2}$ (Fig. 1). The region is drained by Oued Fez and Oued Mekkes and their tributaries. The region offers considerable opportunities in terms of thermal mineral resources with springs of Sidi Harazem, Moulay Yacoub and Ain Allah. However, the region is beginning to suffer from a decline in water resources over the past two decades, which is manifested by the decrease in flows due to the rainfall decrease. The climate of the region is dry and hot in summer and humid and cool in winter with significant seasonal thermal differences and average rainfall of $550 \mathrm{~mm}$. Agriculture and crafts are the main economic activities in the Saïss plain.

\footnotetext{
*manalgarouani@yahoo.fr
} 
To analyze the change in LULC and its impact on LST in the Saïss plain, we selected 18 satellite images from the winters and summers of 1988, 1999, 2009 and 2019 as the main data sources. In the framework of this study, satellite images produced by Landsat 5, 7 and 8 . Images are downloaded from the USGS website (https://glovis.usgs.gov), and have a preprocessing level (Collection 1 level 1) [16]. They are in the form of a quantified and calibrated digital count representing the multispectral image data. Landsat 8 data acquired by both the Operational Land Imager (OLI) and the Thermal Infrared Sensor (TIRS) are provided in integer (16-bit) format. Landsat 5 and 7 products are provided in integer (8-bit) format [16].

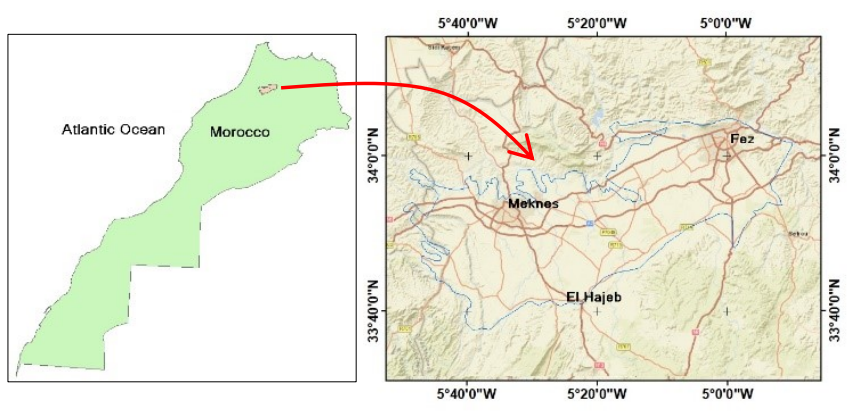

Fig. 1. Location of the study area

\subsection{Methods}

\subsubsection{Land surface temperature retrieval}

For the extraction of physical parameters from Landsat images, we proceeded by several calculations. The algorithm was created by ModelBuilder in ArcGIS 10.8, and it can be used to process LANDSAT5-7 and 8 data. The LST of any Landsat satellite image can be calculated following three steps:

The first step of the algorithm is the input of band 6 for Landsat 5-7 and band 10 for Landsat 8. After inputting bands (the digital counts: DN), the tool uses formulas taken from the USGS webpage [17] for retrieving the top of atmospheric spectral radiance $(L \lambda)$.

The second step of the algorithm is to covert the spectral radiance to brightness temperature $(\mathrm{Tb})$ [17] using the thermal constants provided in the metadata file of Landsat images.

The last step to calculate the LST or the emissivity corrected land surface temperature (TS) is computed based on the Artis and Carnahan model [18]

$$
T s=\frac{T b}{\left(1+\left[\left(\frac{\lambda T b}{\rho}\right) \ln \varepsilon\right]\right)}
$$

Where, Ts: Land surface temperature in $\left({ }^{\circ} \mathrm{C}\right)$; $\mathrm{Tb}$ : Brightness temperature in $\left({ }^{\circ} \mathrm{C}\right) ; \lambda$ : Wavelength of the emitted radiance $(\lambda=10.895) ; \varepsilon$ : Emissivity, $\sigma$ : Boltzmann constant.

\subsubsection{Land use Land cover mapping}

For LULC mapping, we proceeded by the supervised classification method by maximum likelihood algorithm. The process consists of several steps. First, the collection of training samples was carried out. Six mainland use/cover classes have been identified: water bodies, urban, rangelands, irrigated crops, arboriculture and arable lands. An automatic classification was then performed using the maximum likelihood algorithm (Fig. 2). To improve the classification, we conducted post-classification processing (application of a majority filter). The accuracy of the classification was assessed using the confusion matrix [19]. From this matrix, we generated the global precision and the Kappa coefficient.

\section{RESULTS AND DISCUSSION}

\subsection{Land use land cover analysis}

Before the analysis and interpretation of LULC maps, validation of the classification was performed by visual comparison with field reality and by calculation and analysis of the confusion matrix. Using an SQL query in ArcGIS software, the data for the confusion matrix has been extracted. The percentage of overall accuracy and the Kappa coefficient for all classifications exceed $80 \%$. This suggests that the classifications are reliable and accurate [20].

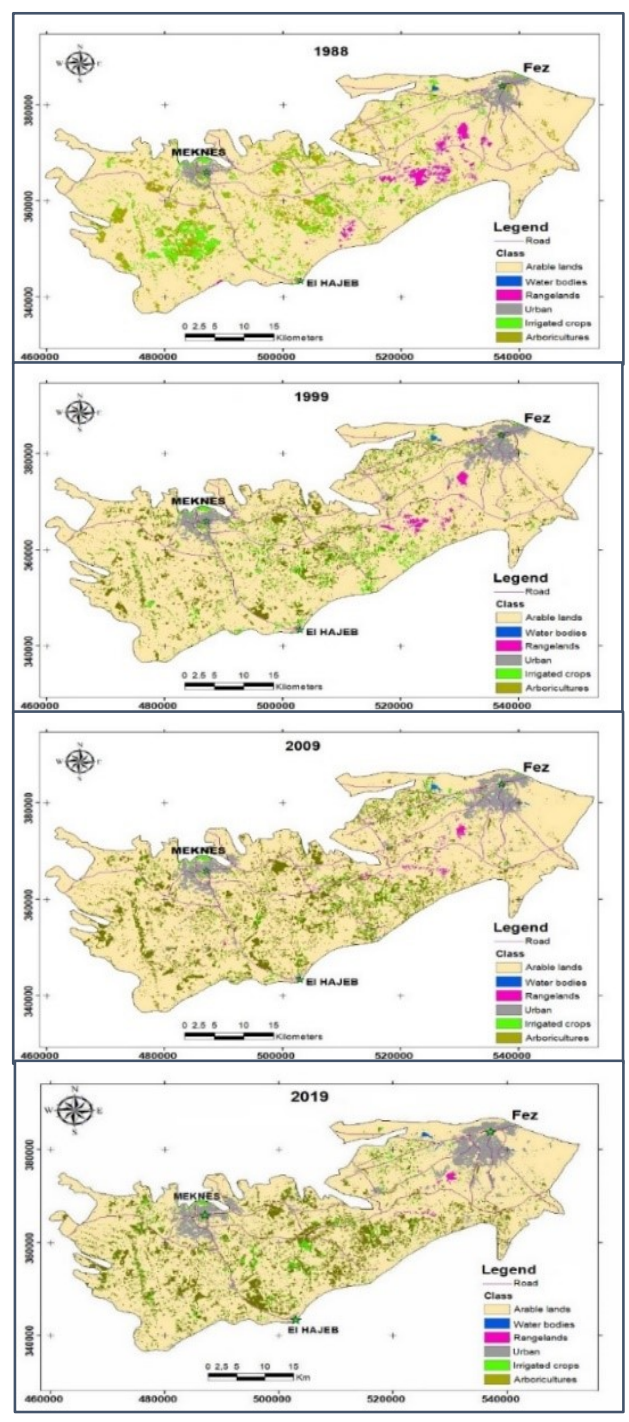

Fig. 2. LULC maps for 1989, 1999, 2009 and 2019. 
The classification results for the region between 1988 and 2019 show a significant change in LULC classes (Fig. 2): an increase in urban, water bodies and arboriculture, and a decrease in rangelands, irrigated crops and arable lands.

\subsection{Determination of LST in Saïss plain}

Figure 3 shows the maps of LST in Saïss Plain during the winter and summer of years: 1988, 1999, 2009 and 2019. The surface temperatures show a variation of an order of -4 to $46^{\circ} \mathrm{C}$ and thus a thermal amplitude of about $50^{\circ} \mathrm{C}$. Throughout the region, there appears a strong thermal heterogeneity: between urban, agricultural, water bodies, etc. The cool zones are well individualized and correspond to urban and arboriculture areas. The warm zones are the agricultural land and rangelands.

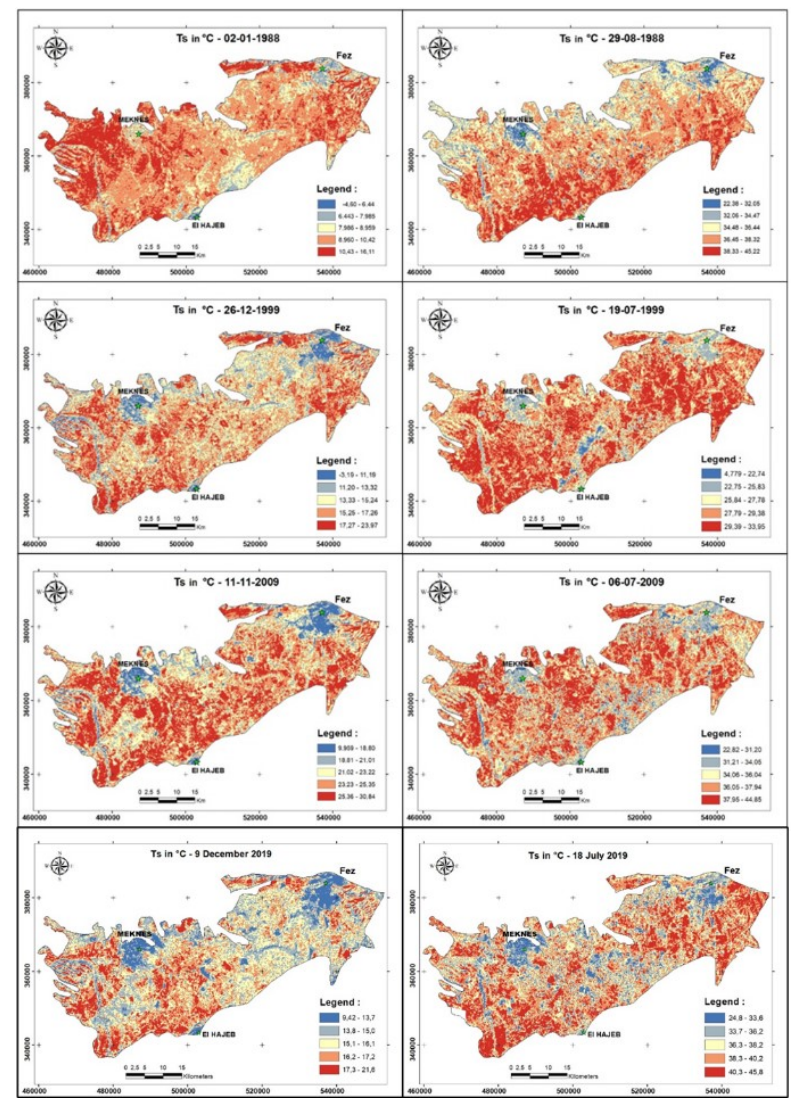

Fig. 3. LST maps during winter and summer for 1988, 1999, 2009 and 2019

\subsection{Ts variation for different LULC types for the period 1988-2019}

To explain the variation in LST for the same land cover over time (Fig. 4), graphs were created [21]. LST increases slightly from water bodies to arable lands. The variation of LST for the same land cover over the years (highest in November 2009 and lowest in January 1988) is explained by the variation in air temperature during these days. For the summer season, LST was low for water bodies, irrigated crops and arboriculture, whereas for rangelands and arable lands was quite high. On the other hand, a cross-section profile in the study area shows that water bodies, urban and arboriculture have average surface temperatures between 32 and $34^{\circ} \mathrm{C}$, while rangelands and arable lands have mean surface temperatures between 37 and $40^{\circ} \mathrm{C}$. During this month, the variation coefficient of LST between water bodies and arable land is $17 \%$.

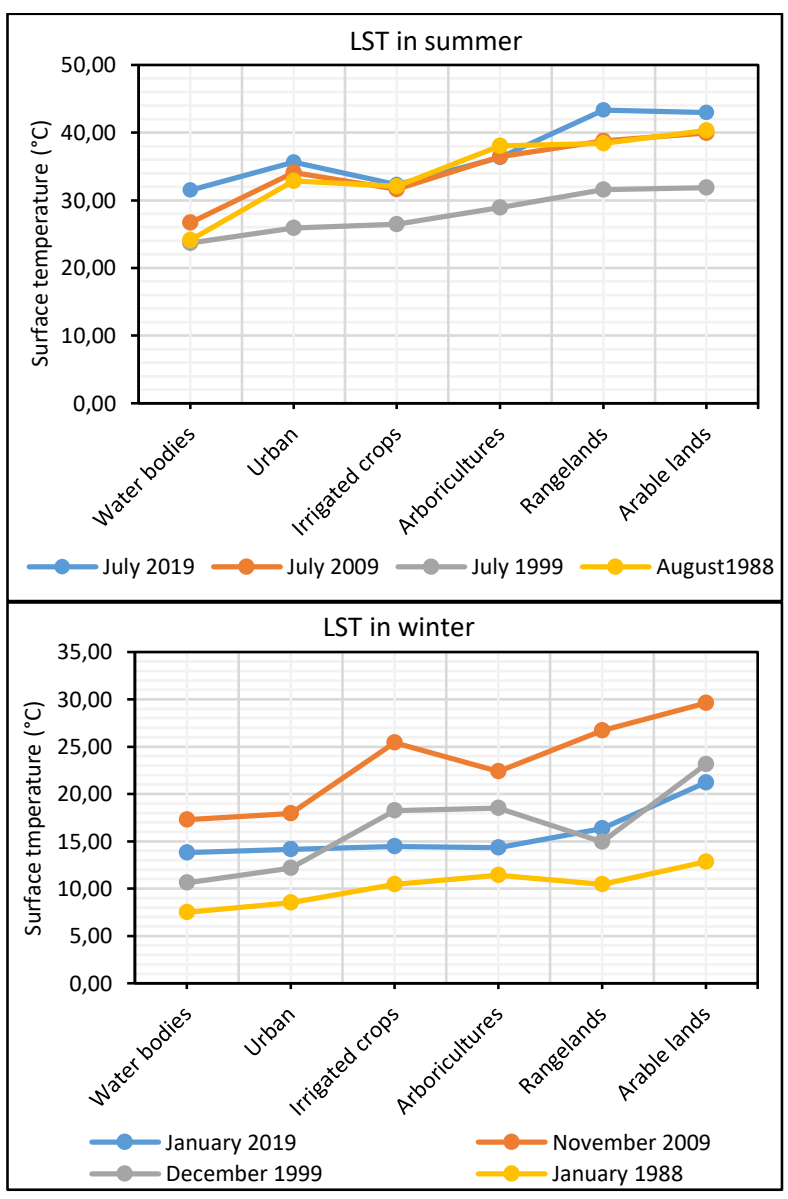

Fig. 4. LST variation in different LULC over time (4 years: winter and summer seasons)

\subsection{Relationship between LST and NDVI}

To highlight the effect of biomass on surface temperature distribution, LST was represented as a function of NDVI [21]. For the same year (One image per month for 2019), for low NDVI (between 0 and 0.1 corresponding to dry bare soil) an increase in surface temperature (Fig. 5). For NDVI values greater than 0.1, the surface temperature decreases as the NDVI values increase, which is quite normal because the increase in biomass reduces the heat release from the surface.

For the years 1988, 1999, 2009 and 2019 (Fig. 6), the results also show a negative correlation between the surface temperature and the vegetation index with very high correlation coefficients $(0.93)$. For all years, land surface temperature decreases as the NDVI values increase. 

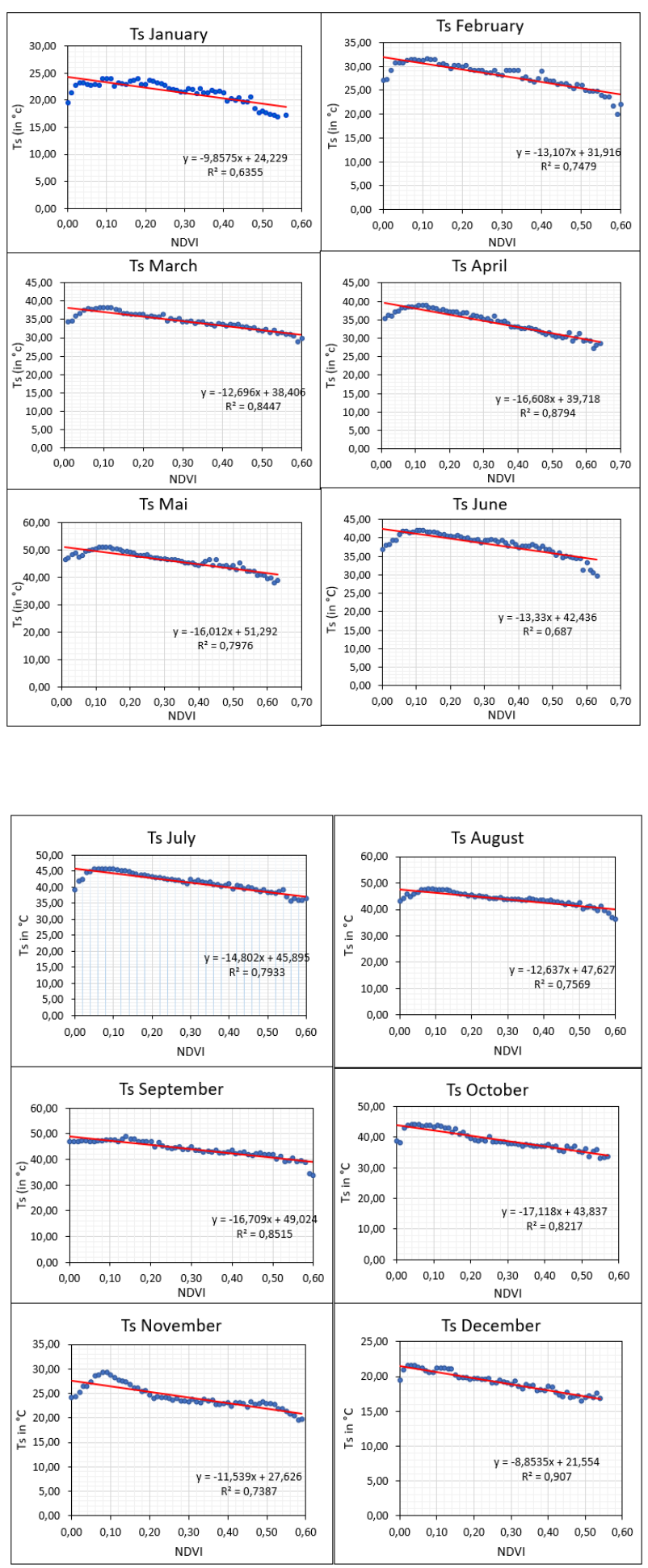

Fig. 5. Correlation between LST and NDVI over 2019 (one image per month)

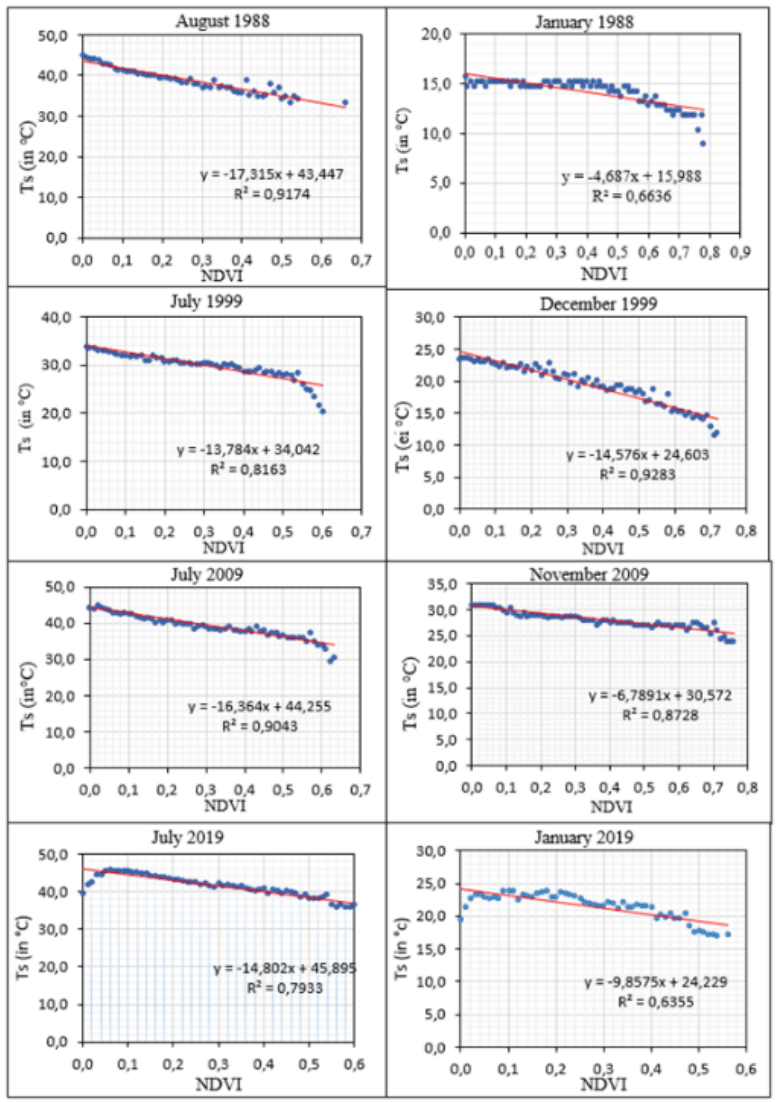

Fig. 6. Correlation between Ts and NDVI for 1988, 1999, 2009 and 2019 (one image in winter and one image in summer)

\section{IV.Conclusion}

Land use/cover mapping showed that the region had undergone a significant evolution, an increase of arboriculture and urban areas to detriment of arable lands and rangelands. Based on these maps, the analysis of spatio-temporal changes in LULC over the period 1988-2019 was carried out. Statistical analyzes were performed to present the relationship between LST and LULC and correlations between LST and NDVI for the period 1988-2019. For all years, a negative correlation between the land surface temperature and the vegetation index with very high correlation coefficients (0.93). From these analyzes, we can say that the land surface temperature varies during phases of plant growth in all seasons and that it is diversified due to the positional influence of the type of existing land use/cover.

\section{References}

1. I.J. Barton, Satellite-derived sea surface temperatures: A comparison between operational, theoretical and experimental algorithms. J. Appl. Meteorol. 31, pp. 432-442(1992)

2. C. Coll, V. Caselles, J.M. Galve, Ground measurements for the validation of land surface temperatures derived from AATSR and MODIS data. Rem. Sens. Environ. 97 pp.288-300 (2005), doi.org/10.1016/j.rse.2005.05.007

3. P. Dash, F. Göttsche, M., F. S. Olesen, H. Fischer, Land surface temperature and emissivity estimation from passive sensor data: Theory and 
practice-current trends. Inter. J. of Remote Sensing, 23, pp. 2563-2594 (2002)

4. J.P. Lagouarde, Y. H. Kerr, Y. Brunet, $A n$ experimental study of angular effects on surface temperature for various plant canopies and bare soils, Agric. Forest Meteorol 77: 167- 190 (1995).

5. Z.L. Li, B. Tang, H. Wu, Satellite-derived land surface temperature: Current status and perspectives. Remote Sensing of Environment 131, pp 14 - 37 (2013).

6. Z. Qin, and A. Karnieli, Progress in remote sensing of land surface temperature and ground emissivity using NOAA-AVHRR data. Inter. J. of Rem. Sens 20: 2367-2393 (1999).

7. T.J. Schmugge, W.P. Kustas, J.C. Ritchie, T. J. Jackson and Al Rango, Remote sensing in hydrology. Advances in Water Resources, 25 (12), pp. 1367-1385 (2002).

8. J. Zhou, J., Zhang, Li., D. Hu, and W. Zhan, Intercomparaison of methods for estimating land surface temperature from Landsat-5 TM image in an arid region with low water vapor in the atmosphere. International Journal of Remote Sensing 33 (8), pp. 2582-2602 (2012).

9. V.V. Serafini, Estimation of the evapotranspiration using surface and satellite data. International journal of remote sensing, 8, pp 1547-1562 (1987).

10. J.C. Price, The potential of Remotely Sensed Thermal Infrared data to Infer Surface Soil Moisture and Evaporation. Water Resources, 16, pp 787-795 (1990).

11. A. Karnieli, N. Agam, R. T. Pinker, M. Anderson, M. L. Imhoff, G. G. Gutman, N. Panov \& A. Goldberg, Use of NDVI and Land Surface Temperature for Drought Assessment: Merits and Limitations. Journal of Climate 23 (3): pp. 618633 (2010). doi.org/10.1175/2009JCLI2900.1

12. T.J. Schmugge, J.C. André, Land Surface Evaporation: Measurements and Parameterization. Springer-Verlag; New York. (1991)

13. M. Mohan, Climate change: evaluation of ecological restoration of Delhi ridge using remote sensing and GIS technologies. International Archives of Photogrammetry and Remote Sensing, vol 33, pp. 886-894 (2000).

14. J. J. Feddema, K. W. Oleson, G. B. Bonan, L. O. Mearns, L. E. Buja, G. A. Meehl, et W. M. Washington, The importance of land-cover change in simulating future climates. Science, pp. 16741678 (2005).

15. H. Yagoub., Cartographie et suivi du couvert végétal des zones semi-arides par l'imagerie satellitaire. Doctorat Es-Science, Université des Sciences et de la Technologie d'Oran Mohamed Boudiaf, Faculté de Physique, 150p (2015).
16. USGS, Landsat collection 1 level 1 product definition. EROS Sioux Falls, South Dakota, USA, $32 \mathrm{p}$ (2019a).

17. USGS, Landsat 8 (L8) Data Users Handbook Version 5.0. EROS Sioux Falls, South (2019b)

18. D.A. Artis, W.H.Carnahan, Survey of emissivity variability in thermography of urban areas. Remote Sens. Environ. 12, pp. 313-329 (1982)

19. S. Bontemps, Cartographie et interprétation de l'évolution du développement territorial par télédétection spatiale au Cambodge. Mémoire de fin d'études de la faculté des Sciences Agronomiques, UCL, Louvain-La-Neuve, 111p (2004).

20. F. Bonn, Précis de télédétection, Volume $2-$ Application thématiques. Presses de l'Université du Québec/ AUPELF, 633 p (1996).

21. M. El Garouani, M. Amyay, A. Lahrach and H.J Oulidi., Land Surface Temperature in Response to Land Use/Cover Change Based on Remote Sensing Data and GIS Techniques: Application to Saïs Plain, Morocco. Journal of Ecological Engineering, 22(7), pp.100-112 (2021). 